\title{
UROMYCES EUPHORBIAE ON EUPHORBIA HIRTA L. FROM GUERREROAND MICHOACAN (MEXICO): FIRST REPORT
}

\author{
Gerardo Vázquez-Marrufo, MA Soledad Vázquez-Garcidueñas ${ }^{1}$ \\ AND IRUM MUKHTAR*
Centro Multidisciplinario de Estudios en Biotecnología, Facultad de Medicina Veterinaria y Zootecnia, Posta Veterinaria, Km 9.5 Carretera Morelia-Zinapécuaro, Col. La Palma, Tarímbaro, Michoacán, Mexico.

Key words: Euphorbia hirta, Urediniospores, Uromyces euphorbiae, Rust pustules

\begin{abstract}
During August and November, 2013, leaves of Euphorbia hirta L. were found with a rust disease in Taxco and Morelia cities in Guerrero and Michoacán states, respectively. The pustules of rust were orange yellow to dark brown in color and were observed on lower and upper side of leaves. Necrotic red-purple or dark brown spots were also observed upper surface of leaves with pustules on the lower surface. On the basis of morphological characteristics, the rust species was identified as Uromyces euphorbiae. This is the new record of $U$. euphorbiae on E. hirta in Guerrero and Michoacán states in Mexico.
\end{abstract}

Euphorbia hirta L. is a wild herbaceous plant and has been used as remedy for different diseases like asthma, bronchitis, intestinal problems, treatment of cancer and skin diseases in various states of Mexico (Martinez et al. 1995). A rust disease was observed on E. hirta leaves in Taxco (Guerrero state) and Morelia (Michoacán state) during August and November, 2013. Numerous rust pustules (uredinia) were observed on lower and upper sides of plant leaves. However, leaves with red-purple or dark brown necrotic spots with pustules on the lower surface were also observed. Density of uredinia was observed to be a few to many per leaf in same plant. Uredinia were hypophyllous, orange-yellow to dark brown sub-epidermal erumpent, powdery (Fig.1A). Diameter of uredinium was $0.5-2.5 \mathrm{~mm}$ with $0.2-0.3 \mathrm{~mm}$ in height, becoming a dark brown in color when mature. Urediniospores were pale brown to cinnamon-brown often with a large nucleus, pedicel of 6 - $18 \mu \mathrm{m}$ in length, spherical, ellipsoidal and pyriform, from $15-19 \mu \mathrm{m}$ $\times 18-23 \mu \mathrm{m}$ with spinulate walls of $1.5-2.0 \mu \mathrm{m}$ (Fig.1B). Urediniospores had $3-4$ germ pores, more or less equatorial, or a few more pores and seemingly scattered. Telia were present on both sides of leaves, powdery dark choclate-brown, $0.4-1 \mathrm{~mm}$ in diameter, scattered, erumpent, ruptured epidermis inconspicuous and pulvinate. Teliospores were cinnamon-brown, moderately verrucose with short hyaline pedicel, broadly ellipsoid obovoid $15-18 \times 18-26 \mu \mathrm{m}$ with wall thickness of 1.0 - $1.5 \mu \mathrm{m}$. A lighter colored, conical papilla was also observed in teliospores.

Scanning electron microscopy (SEM) revealed that the uredinia were characterized by a raised peridium (convex) which emerged from leaf epidermis. Matured uredinium showed a ruptured leaf epidermis and internal large number of urediniospores of globoid or ellipsoid in shapes with numerous conical ecinulations. Urediniospores are borne singly on a pedicel (Fig.1C).

*Author for correspondence: <erumm21@yahoo.com>. ${ }^{1}$ División de Estudios de Posgrado, Facultad de Ciencias Médicas y Biológicas “Dr. Ignacio Chávez”, Bosque Cuauhtémoc, Col. Centro. Morelia, Michoacán, Mexico. Universidad Michoacana de San Nicolás de Hidalgo 


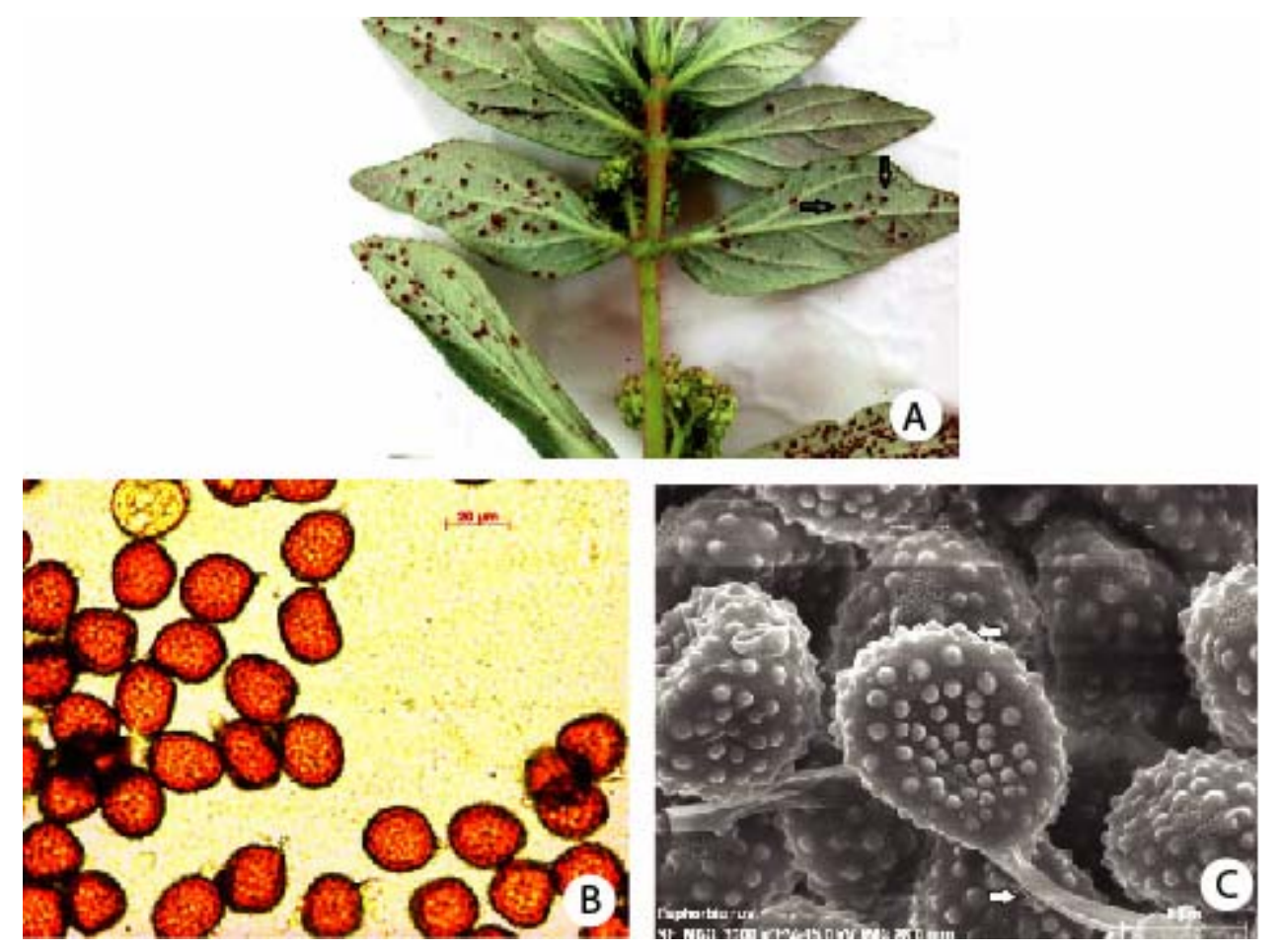

Fig. 1A-C. Rust of Euphorbia hirta. A. Uromyces euphorbiae infection on lower side of leaf surface of Euphorbia hirta. Arrow heads indicate uredinia with a raised peridium. B. Various shapes of spores (40X), C. SEM micrograph (3000X) shows urediniospores with echinulation and pedicel (arrow heads).

Based on morphological characteristics, the fungus was identified as Uromyces euphorbiae (Kaneko and Hiratsuka 1984, Monoson and Prose 1983). Previously, this rust was reported on E. hirta in Sinaloa state (north of Mexico), more than 34 years ago (León-Gallegos and Cummins 1981). This is the first record of U. euphorbiae on E. hirta in Guerrero and Michoacán states in Mexico.

\section{Acknowledgement}

The authors are thankful to the Ministry of Foreign Affairs, Mexico for awarding postdoctoral fellowship funding to Dr. Irum Mukhtar and to the Institute of Metallurgical Research, Universidad Michoacana de San Nicolás de Hidalgo (UMSNH), Morelia, Michoacán, Mexico, for technical support in scanning electron microscopy (SEM).

\section{References}

Kaneko S and Hiratsuka N 1984. Some criteria in taxonomy of melampsoraceous rust species. Rep. Tottori Mycol. Inst. 22: 141-147.

León-Gallegos HM and Cummins GG 1981. Uredinales (Royas) de México. México: Vol. I and II: Instituto Nacional de Investigaciones Agrícolas, Culiacán, Mexico. pp. 438.

Martinez MA, Evangelist V, Mendoza M, Morales G and Toledo G 1995. Wong catálogo de plantas utiles de la Sierra Norte de Puebla, Mexico. Instituto de Biología UNAM, Mexico. pp. 110.

Monoson HL and Prose SE. 1983. Autoecious Uromyces that Infect New-World Euphorbiaceae. Mycologia 75(3): 436-450.

(Manuscript received on 9 June, 2014; revised on 13 August, 2014) 